http://dx.doi.org/10.1038/s41598-017-14244-9

3. Janda JM, Abbott SL. 16S rRNA gene sequencing for bacterial identification in the diagnostic laboratory: pluses, perils, and pitfalls. J Clin Microbiol. 2007;45:2761-4. http://dx.doi.org/ 10.1128/JCM.01228-07

4. Lee I, Ouk Kim Y, Park SC, Chun J. OrthoANI: an improved algorithm and software for calculating average nucleotide identity. Int J Syst Evol Microbiol. 2016;66:1100-3. http://dx.doi.org/10.1099/ijsem.0.000760

5. Meier-Kolthoff JP, Auch AF, Klenk H-P, Göker M. Genome sequence-based species delimitation with confidence intervals and improved distance functions. BMC Bioinformatics. 2013;14:60. http://dx.doi.org/10.1186/1471-2105-14-60

6. Lin JN, Lai CH, Yang CH, Huang YH, Lin HH. Complete genome sequence of Elizabethkingia miricola strain EM798-26 isolated from the blood of a cancer patient. Genome Announc. 2018;6:e01408-17. http://dx.doi.org/10.1128/genomeA.01408-17

7. Hsu MS, Liao CH, Huang YT, Liu CY, Yang CJ, Kao KL, et al. Clinical features, antimicrobial susceptibilities, and outcomes of Elizabethkingia meningoseptica (Chryseobacterium meningosepticum) bacteremia at a medical center in Taiwan, 1999-2006. Eur J Clin Microbiol Infect Dis. 2011;30:1271-8. http://dx.doi.org/10.1007/s10096-011-1223-0

8. Lau SK, Chow WN, Foo CH, Curreem SO, Lo GC, Teng JL, et al. Elizabethkingia anophelis bacteremia is associated with clinically significant infections and high mortality. Sci Rep. 2016;6:26045. http://dx.doi.org/10.1038/srep26045

9. Perrin A, Larsonneur E, Nicholson AC, Edwards DJ, Gundlach KM, Whitney AM, et al. Evolutionary dynamics and genomic features of the Elizabethkingia anophelis 2015 to 2016 Wisconsin outbreak strain. Nat Commun. 2017;8:15483. http://dx.doi.org/10.1038/ncomms15483

10. Han MS, Kim H, Lee Y, Kim M, Ku NS, Choi JY, et al. Relative prevalence and antimicrobial susceptibility of clinical isolates of Elizabethkingia species based on 16S rRNA gene sequencing. J Clin Microbiol. 2017;55:274-80. http://dx.doi.org/ 10.1128/JCM.01637-16

Address for correspondence: Jiun-Nong Lin, E-Da Hospital, Division of Infectious Diseases, Department of Internal Medicine, No. 1, Yida Road, Jiaosu Village, Yanchao District, Kaohsiung 824, Taiwan; email: jinoli@kmu.edu.tw

\section{Human Enterovirus C105, China, 2017}

\author{
Maozhong Li, ${ }^{1}$ Tiegang Zhang, ${ }^{1}$ Cheng Gong, \\ Aihua Li, Ming Luo, Mei Dong, Fang Huang
}

Author affiliation: Beijing Center for Disease Prevention and Control, Beijing, China

${ }^{1}$ These authors contributed equally to this article.
DOI: https://doi.org/10.3201/eid2507.180874

We report a case of enterovirus C105 infection in an 11-year-old girl with lower respiratory tract symptoms that was identified through the Respiratory Virus Surveillance System, which covers 30 sentinel hospitals in all 16 districts of Beijing, China. The presence of this virus strain in China confirmed its geographically wide distribution.

$\mathrm{E}$ nteroviruses are small, nonenveloped RNA viruses that cause illnesses in humans ranging from mild to severe (1). Fifteen species of enterovirus are known, 7 of which are known to infect humans. These species include enterovirus $\mathrm{A}-\mathrm{D}$ and rhinovirus $\mathrm{A}-\mathrm{C}(1,2)$. The newly emerging genotype C105 (EV-C105) represents a novel monophyletic clade of enterovirus $C$; this strain was identified in 2010 in the Democratic Republic of the Congo (strain 34S) $(3,4)$. EV-C105 cases from Italy (Pavia/8376, Pavia/9095), Romania (ROM31), the United States (USA/OK/201419362), New Zealand (strains not available), and Burundi (BU77, BU5) have been identified and characterized, suggesting that the spread of EV-C105 could be wider than previously hypothesized (5). Here, we report a detected case of EV-C105 in an 11-year-old girl with lower respiratory tract symptoms in Beijing, China.

The Beijing Center for Disease Prevention and Control established the Respiratory Virus Surveillance System (RVSS) in 2014. The RVSS tracks patients with respiratory tract infections (RTIs) and pneumonia in 30 sentinel hospitals throughout Beijing. The RVSS is an active system, designed to alert for future outbreaks of respiratory infections. To study enterovirus infections, we tested 24,093 clinical specimens (nasopharyngeal swab, sputum, and alveolar lavage fluid) from patients with RTIs that were reported through RVSS during June 2014-December 2017. RVSS classifies persons $<14$ years of age as children and those $\geq 14$ years of age as adults. The ages of the reported patients ranged from 8 months to 93 years (median 33.5 years, mean 37.9 years).

We screened all samples using real-time PCR for influenza virus, parainfluenza virus types $1-4$, respiratory syncytial virus, coronaviruses (229E, NL63, HKU1, and OC43), metapneumovirus, adenovirus, bocavirus, and enteroviruses (6). Overall, $445(445 / 7,122 ; 6.2 \%)$ children and $276(276 / 16,971 ; 1.6 \%)$ adults were positive for enterovirus or other respiratory viruses.

We further genotyped enterovirus-positive samples with primers sequentially targeting the viral protein (VP) 1 region $(7,8)$. We obtained a 699-nt amplicon of EV-C105 from a nasopharyngeal swab sample collected at the time of a hospital visit (GenBank accession no. KX910099). The patient was an 11-year-old girl with no underlying disease who was brought to the outpatient clinic of the Beijing Children's 
Figure. Phylogenetic tree of EV-C105 from a patient in Beijing, China (black dot) and reference isolates from different locations. We estimated the phylogenetic relationships of complete or near-complete EV-C105 genomes using the neighborjoining method with 1,000 replicates bootstrapped by using MEGA version 6.06 software (http://www.

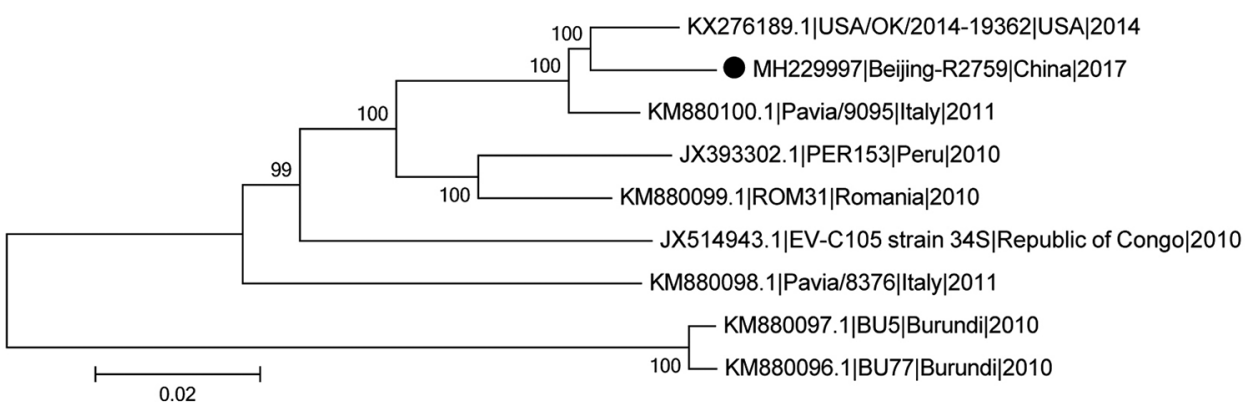
megasoftware.net). Numbers along branches indicate bootstrap percentages. Isolates are identified by GenBank accession number, strain name, location, and year. Scale bar indicates nucleotide substitutions per site. EV-C105, enterovirus C105.

Hospital on May 23, 2016, with an 8-day history of fever (highest temperature $38.7^{\circ} \mathrm{C}$ ), coughing, and difficulty breathing. Blood tests in the clinic showed total leukocyte count $1.41 \times 10^{10}$ cells/L; neutrophils, $79.2 \%$; lymphocytes, $12.1 \%$; total platelet count, $5.2 \times 10^{11} / \mathrm{L}$; and hemoglobin, $130 \mathrm{~g} / \mathrm{L}$. Chest radiographs showed thickness or turbulence in the texture in both lungs, which was diagnosed as pneumonia. She received supportive treatment and received antimicrobial drugs empirically before being sent home the same day. She was not hospitalized during her illness. According to a follow-up survey, she recovered 14 days later. We detected no other respiratory pathogens in this patient.

BLAST analysis (http://blast.ncbi.nlm.nih.gov/Blast. cgi) of the amplicon (Beijing-R2759) showed that the sequences had 98\% identity with the USA/OK/2014-19362 strain (GenBank accession no. KX276189.1) and 91.4\% with the reference prototype genotype (EV-C105 strain 34S; accession no. JX514943). Phylogenetic analysis of the VP1 gene performed with MEGA version 6.06 software (http://www.megasoftware.net) showed that BeijingR2759 belonged to genotype EV-C105.

To further characterize this virus strain, we amplified the genome sequence directly from the nasopharyngeal swab sample using reverse transcription PCR with overlapping primers; we sequenced each amplicon 4 times using the Sanger method. We assembled sequences using Lasergene version 5.01 (DNAStar Inc., https://www.dnastar. com). The genome of Beijing-R2759 (GenBank accession no. MH229997) was 7,316 nt, including 6,618 nt in open reading frame. The EV-C105 polyprotein sequence for this strain shares $96.6 \%-99.4 \%$ amino acid identity with 8 of the EV-C105 sequences in GenBank: $96.6 \%$ with accession no. KM880097 (Burundi); 96.8\% with accession no. KM880096 (Burundi); 97.7\% with accession no. JX393302 (Peru); 98.5\% with accession no. JX514943 (Republic of the Congo); $98.6 \%$ with accession no. KM880098 (Italy); 98.8\% with accession no. KM880099 (Romania); 99.3\% with accession no. KX276189 (United States); and 99.4\% with accession no. KM880100 (Italy).
The full length of the Beijing-R2759 VP1 gene was 888 nt. The deduced amino acid sequence in VP1 had $94.9 \%-100 \%$ identity with those from Italy, Peru, Republic of the Congo, and the United States. Alignment results analysis of VP1 aa sequences showed differences between the strains isolated in this study $\left(\mathrm{Met}^{25}, \mathrm{Asp}^{138}, \mathrm{Ser}^{207}\right)$ and EV-C105 strain 34S $\left(\mathrm{Val}^{25}\right.$, Glu ${ }^{138}$, and $\left.\mathrm{Ala}^{207}\right)$. In this study, we grouped Beijing-R2759 with the strain obtained from the United States in 2014 (Figure). We observed a similar relationship in the phylogenic tree of the VP1 gene. These findings indicate that Beijing-R2759 is closely related to the EV-C105 strain reported in the United States.

Our report confirms that the distribution of EV-C105 is geographically wider than previously believed. A greater awareness of EV-C105 may enable improved detection of this virus (9). In addition, our findings show the utility of the RVSS in assessing the patterns of circulation of enterovirus genotypes and detecting enterovirus outbreaks for the purpose of early warning.

This work was supported by the National Major Science and Technology Project for Control and Prevention of Major Infectious Diseases of China (2017ZX101304), the Beijing Municipal Science and Technology Commission (Z151100003915140), and the Capital Medical Development and Scientific Research Fund (2016-2-3011).

\section{About the Author}

Dr. Li is an assistant researcher in the Institute for Immunization and Prevention of the Beijing Center for Disease Prevention and Control. His research interests include early warning systems and respiratory pathogens.

\section{References}

1. Lukashev AN, Drexler JF, Kotova VO, Amjaga EN, Reznik VI, Gmyl AP, et al. Novel serotypes 105 and 116 are members of distinct subgroups of human enterovirus C. J Gen Virol. 2012;93:2357-62. http://dx.doi.org/10.1099/vir.0.043216-0

2. Van Leer-Buter CC, Poelman R, Borger R, Niesters HG. Newly identified enterovirus $\mathrm{C}$ genotypes, identified in the Netherlands 
through routine sequencing of all enteroviruses detected in clinical materials from 2008 to 2015. J Clin Microbiol. 2016;54:2306-14. http://dx.doi.org/10.1128/JCM.00207-16

3. Grard G, Drexler JF, Lekana-Douki S, Caron M, Lukashev A, Nkoghe D, et al. Type 1 wild poliovirus and putative enterovirus 109 in an outbreak of acute flaccid paralysis in Congo, OctoberNovember 2010. Euro Surveill. 2010;15:pii=19723.

4. Richter J, Tryfonos C, Panagiotou C, Nikolaou E, Koliou M, Christodoulou C. Newly emerging $\mathrm{C}$ group enteroviruses may elude diagnosis due to a divergent $5^{\prime}$-UTR. Int J Infect Dis. 2013; 17:e1245-8.

5. Todd A, Taylor S, Huang QS. Identification of enterovirus C105 for the first time in New Zealand. Western Pac Surveill Response J. 2015;6:60-2. http://dx.doi.org/10.5365/wpsar.2014.5.4.003

6. Zhang T, Ren L, Luo M, Li A, Gong C, Chen M, et al. Enterovirus D68-associated severe pneumonia, China, 2014. Emerg Infect Dis. 2015;21:916-8. http://dx.doi.org/10.3201/eid2105.150036

7. Nix WA, Oberste MS, Pallansch MA. Sensitive, seminested PCR amplification of VP1 sequences for direct identification of all enterovirus serotypes from original clinical specimens. J Clin Microbiol. 2006;44:2698-704. http://dx.doi.org/10.1128/JCM.00542-06

8. Oberste MS, Penaranda S, Rogers SL, Henderson E, Nix WA. Comparative evaluation of Taqman real-time PCR and semi-nested VP1 PCR for detection of enteroviruses in clinical specimens. J Clin Virol. 2010;49:73-4.

9. Barnadas C, Midgley SE, Skov MN, Jensen L, Poulsen MW, Fischer TK. An enhanced enterovirus surveillance system allows identification and characterization of rare and emerging respiratory enteroviruses in Denmark, 2015-16. J Clin Virol. 2017;93:40-4.

Address for correspondence: Fang Huang, Beijing Center for Disease Prevention and Control, Institute for Communicable Disease Control and Prevention, No. 16, Hepingli Middle Av, Dongcheng District, Beijing 100013, China; email: hhffxdd@126.com

\section{Recent Findings of Potentially Lethal Salamander Fungus Batrachochytrium salamandrivorans}

\author{
David Lastra González, Vojtech Baláž, \\ Milič Solský, Barbora Thumsová, \\ Krzysztof Kolenda, Anna Najbar, \\ Bartłomiej Najbar, Matej Kautman, Petr Chajma, \\ Monika Balogová, Jiří Vojar
}

Author affiliations: Czech University of Life Sciences, Prague, Czech Republic (D. Lastra González, M. Solský, B. Thumsová, P. Chajma, J. Vojar); University of Veterinary and Pharmaceutical Sciences, Brno, Czech Republic (V. Baláž, M. Kautman); University of Wrocławski, Wroclaw, Poland (K. Kolenda,
A. Najbar); University of Zielona Góra, Lubuskie, Poland

(B. Najbar); Slovak Academy of Sciences, Košice, Slovakia

(M. Kautman); Pavol Jozef Šafárik University in Košice, Košice

(M. Balogová)

DOI: https://doi.org/10.3201/eid2507.181001

The distribution of the chytrid fungus Batrachochytrium salamandrivorans continues to expand in Europe. During 2014-2018, we collected 1,135 samples from salamanders and newts in 6 countries in Europe. We identified 5 cases of $B$. salamandrivorans in a wild population in Spain but none in central Europe or the Balkan Peninsula.

$\mathrm{C}$ hytridiomycosis, an amphibian disease caused by the chytrid fungi Batrachochytrium dendrobatidis and $B$. salamandrivorans, is responsible for declines of amphibian populations worldwide (1). The recently discovered $B$. salamandrivorans (2) is severely impacting salamanders and newts in Europe $(3,4)$. This emerging fungal pathogen infects the skin of caudates and causes lethal lesions (2). It most likely was introduced to Europe by the pet salamander trade from Southeast Asia (3). In Europe, the Netherlands, Belgium, and Germany have confirmed B. salamandrivorans in wild caudates; the United Kingdom, Germany, and Spain have confirmed the fungus in captive animals $(5,6)$. Several countries have established trade regulations (5) and a recent European Union decision, no. 2018/320, implements measures to protect against the spread of $B$. salamandrivorans via traded salamanders (7). The World Organisation for Animal Health listed infection with $B$. salamandrivorans as a notifiable disease in 2017. In addition to controlling the amphibian pet trade, surveillance of the pathogen is urgently needed to establish disease intervention strategies in affected areas and prevention in $B$. salamandrivorans-free regions.

During 2014-2018, we collected 1,135 samples directly for the detection of B. salamandrivorans or as a part of unrelated studies. Samples came from 10 amphibian species at 47 sites in 6 countries in Europe. Most samples came from the fire salamander, Salamandra salamandra, which is a known suitable host for $B$. salamandrivorans (3), and the palmate newt, Lissotriton helveticus, which is known to be resistant to B. salamandrivorans (Appendix Table 1, http://wwwnc. cdc.gov/EID/article/25/7/18-1001-App1.pdf).

Most samples were skin swabs collected by following the standard procedure for sampling of amphibian chytrid fungi (8). A smaller portion of samples was toe clippings (Appendix Table 2). We extracted genomic DNA following the protocol of Blooi et al. (9), and 2 laboratories with different equipment tested for $B$. salamandrivorans. Samples from Spain and the Czech Republic initially were analyzed at the Czech University of Life Sciences (Prague, Czech 